\title{
WOOD AND GENERATIVE ALGORITHMS FOR THE COMPARISON BETWEEN MODELS AND REALITY
}

\author{
Fabio Bianconi ${ }^{1}$, Marco Filippucci ${ }^{1}$, Giulia Pelliccia ${ }^{1 *}$ \\ ${ }^{1}$ Department of Civil and Environmental Engineering, University of Perugia, via G. Duranti 9306125 Perugia - \\ fabio.bianconi@unipg.it, marco.filippucci@unipg.it, giulia.pelliccia@outlook.it
}

KEY WORDS: Multiparametric Optimization, Generative Algorithms, Energy Optimization, Wooden Structures, Digital Simulation, Sensor Data, Digital Twin

\begin{abstract}
:
This study examines the emblematic case of a test room and its relation to digital modelling. This space is the result of a multioptimization process that has been physically built for the verification of the initial hypotheses. As a result, it is actually a Physical Twin, designed to be transformable by removing a wall. The same space, on the other hand, has become useful for testing the Digital Twin logic by associating a BIM model with a dynamic representation of the data captured by the sensors. The representation is thus placed at the core of this cyclic phase between reality and representation, with the goal of validating the proposed theories through empirical practice, improving digital computational ability, and identifying pathways for monitoring space's interactions with the environment and those who live in it.
\end{abstract}

\section{INTRODUCTION}

The modern definition of Digital Twin is a conceptual and substantive extension of the importance of digital models, which are "mirror images" (Batty, 2018) of experiences occurring in physical space that are transferred to the virtual world to ensure new management systems. In the ever-expanding theme of digitization (Mitchell, 1995; Lenka et al., 2016), which is inherent in the fourth industrial revolution (Kamarul Bahrin et al., 2016; Schwab, 2016) and thanks to IoT sensors (Gubbi et al., 2013; Xu et al., 2014), anything that can be monitored in physical space can be translated into virtual, multifaceted space (Iansiti and Lakhani, 2015) where data can be converted into information and computational power can be used to simulate the many aspects of shape.

This topic, which began with Nasa (Glaessgen and Stargel, 2012), has a wide range of applications in the construction industry, especially in energy analysis and monitoring (Marszal et al., 2011; Shi and Yang, 2013). According to the directives 2010/31/EU e 2018/844/EU ('Directive 2010/31/EU of the European Parliament and of the Council of 19 May 2010 on the energy performance of buildings', 2010; 'Directive (EU) 2018/844 of the European Parliament and of the Council of 30 May 2018 amending Directive 2010/31/EU on the energy performance of buildings and Directive 2012/27/EU on energy efficiency', 2018), in order to minimize energy usage and increase overall building energy quality, new buildings in Europe must meet nZEB standards (Rodriguez-Ubinas et al., 2014), as buildings are responsible for $40 \%$ of $\mathrm{CO}_{2}$ emissions and energy consumption (Tian et al., 2018). The efficiency of a building is a significant requirement of today's market, which is rediscovering the importance of wooden structures for these reasons (Hoadley, 2000; O'Connor and Dangerfield, 2004; Wood handbook - Wood as an engineering material, 2010; Cabeza et al., 2013; Holstov et al., 2017).

Thanks to manufacturing processes (Oxman and Oxman, 2010; Gramazio et al., 2014; Wood et al., 2016a, 2016b; Falamarzi and Correa Zuluaga, 2019) that are linked to mass customization
(Pine and Slessor, 1999; Anderson, 2002; Kolarevic, 2015; Paoletti, 2017; Bianconi et al., 2019), wood design is enhanced by the digital (Bianconi and Filippucci, 2019a). Wood is a natural and smart material (Ugolev, 2014), that can be transformed by digital processes (Menges, 2009; Menges et al., 2017; Willmann et al., 2017). The use of generative logics (Schumacher, 2011; Bianconi and Filippucci, 2017; Chen and Sass, 2017) in conjunction with Artificial Intelligence (Bianconi and Filippucci, 2019b) to create form-finding processes (Bergmann and Hildebrand, 2015; Weinand, 2016; Hemmerling and Cocchiarella, 2018) that define the best solutions is particularly interesting.

These concepts are then coupled with the BIM approach, which is a further transformation in design logic aimed at managing knowledge in the same environment. This is essentially a cultural as well as a technological revolution (Eastman, 2011). The requirement to use BIM was only recently introduced into Italian law (Ministerial Decree 560/2017). A key date on this road can be found in the year 2002, when Autodesk released a White Paper in which the term "Building Information Modeling" was used for the first time. Even though there are still many gaps to fill (Dainty et al., 2015), the advantages of BIM are moving various figures involved in building processes (Smith, 2014) thanks to its obvious benefits (Khanzode et al., 2008; Barlish and Sullivan, 2012; Bryde et al., 2013). As a result, BIM is a Virtual Environment Platform (VMP) capable of storing, processing, and mapping various types of data (Zheng et al., 2019).

The research is being conducted in this field as part of a collaboration between the Department of Civil and Environmental Engineering and Abitare+, a local innovative wood construction start-up, with the aim of triggering product and service innovation. The research begins with the development of generative models with the goal of multioptimizing the form, energy consumptions, structure, and cost of wooden houses, and it ends with the integration of BIM models.

\footnotetext{
${ }^{*}$ Corresponding author.
} 


\section{BACKGROUND}

The analysis of generative models is followed by a proposal for an integrated mass customization-based design and manufacturing process, aimed primarily at wood construction technicians and specialists but also useful as a dissemination tool for students and researchers. First of all, the research aims to provide personalized housing designs (Bianconi et al., 2019), identifying a range of design solutions that ensure genetic algorithms are used to adapt and optimize the architectural model. The design concept is focused on the analysis of local codes and X-Lam and Platform-Frame building systems with the goal of reducing waste and optimizing the construction process. Energy consumption, thermal and visual comfort, as well as price, were evaluated with the construction company and through iterative processes. The results of this first study, which began with the selection of solutions available to the company, have prompted a closer examination of each element that makes up the building envelope.

The focus of the investigation then shifted to improving the energy efficiency of wooden structures that had previously been customized to meet the location's specific requirements. The aim in this case is to use generative design tools to optimize the preliminary cost and efficiency of wood walls for X-Lam and Platform-Frame structures, with the goal of comparing the actual performance of the built solutions (Seccaroni and Pelliccia, 2019). As a result, the described workflow begins with the implementation of generative algorithms that return thermal

\section{MULTIPARAMETRIC OPTIMIZATION}

\section{MATERIAL SETTINGS}

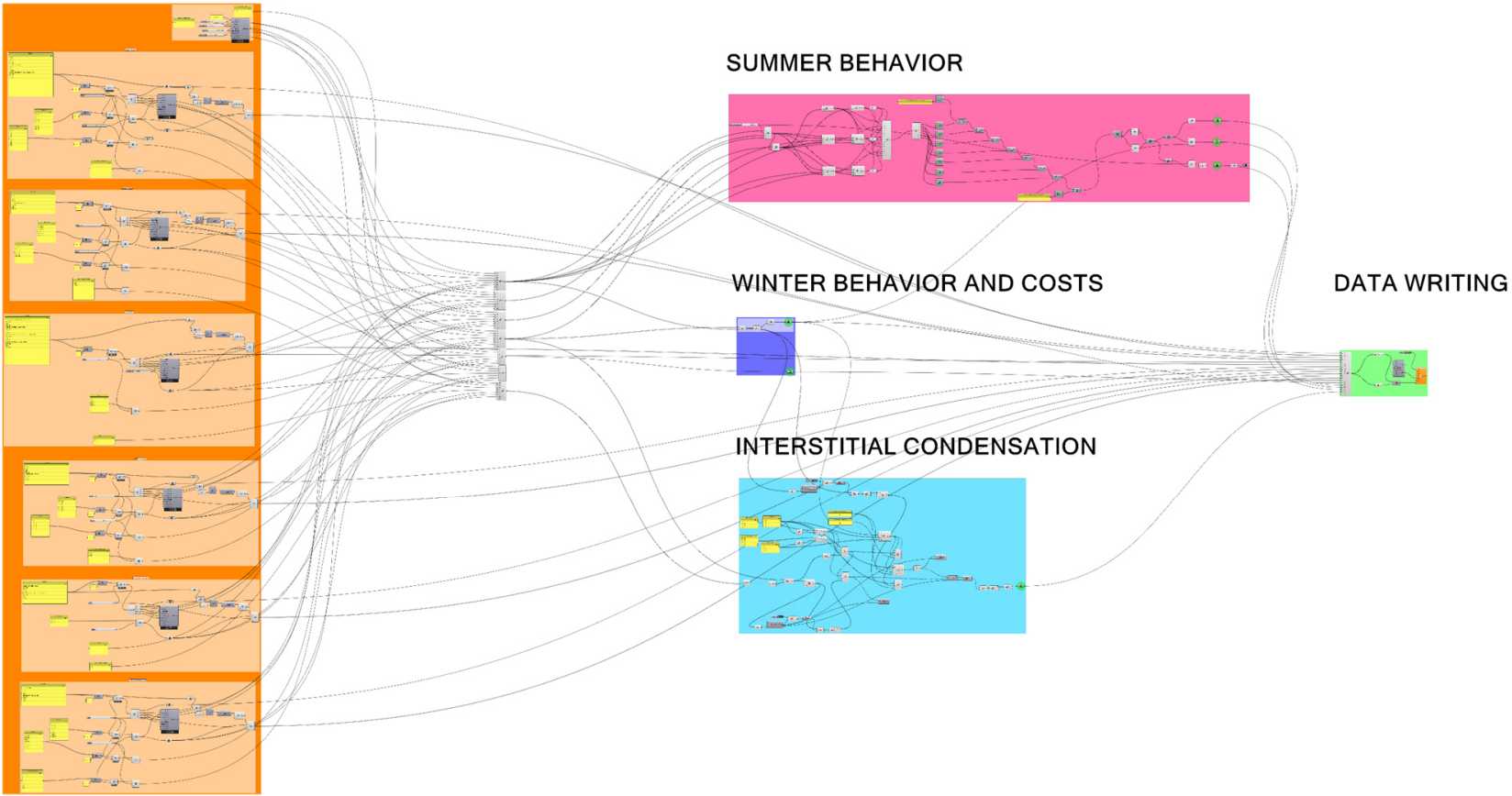

Figure 1. The algorithm combines different materials and thicknesses and evaluates the energy performance of the walls.
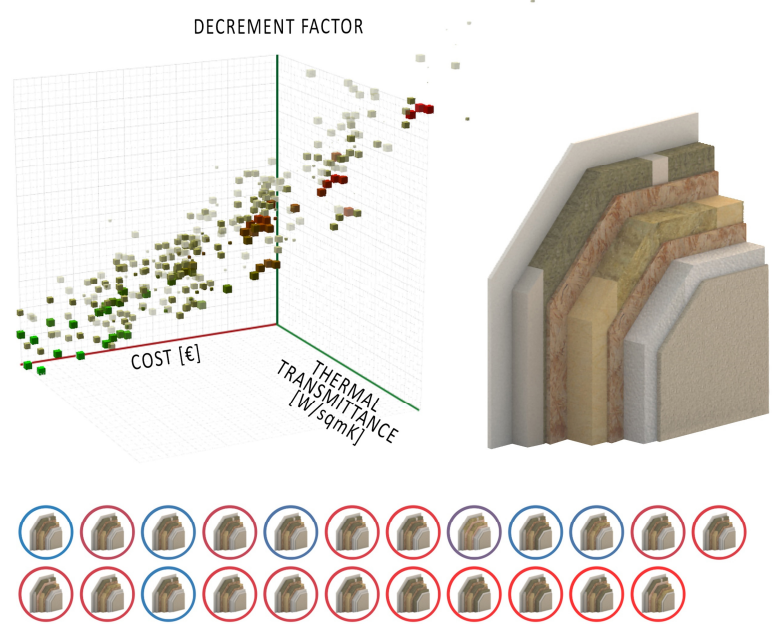

Figure 2. The multi-parametric wall optimization allows the selection of different wall configurations. transmittance, decrement factor, time shift, costs, and verify the absence of interstitial condensation while varying the wall materials and thicknesses from time to time (Rossi and Rocco, 2014; Aste et al., 2015) (Fig. 1). The selected parameters can be processed in a multi-optimization path based on evolutionary algorithms (Diakaki et al., 2008), in which more than 5000 possible material and thickness combinations have been automatically analyzed. The best solutions can thus be selected, identifying the Pareto front (Wright et al., 2002; Wang et al., 2005) in which the combinations simultaneously present optimal values of the various parameters that determine the wall's behavior in summer and winter, as well as the overall cost (Fig. 2).

Through the construction of a test room, the study shifted then from virtual to physical: this is an abstracted representation of a wooden house reduced to the size of a paradigmatic space.

\section{RESEARCH OBJECTIVES}

The research's background demonstrates how the model's basis is digital representation. In this case, the logics inherent in the 
Digital Twin find an interesting inversion, where reality derives from representation, rather than the opposite. As a result, the process can be divided into three phases: simulation and multiparametric optimization of building performance, construction of the test room and data collection, and implementation of the Digital Twin for real-time data exchange.

Therefore, the aim of this study is to examine the relationship between digital and physical in an experimental process whose phases are linked to specific issues. First, it is interesting to investigate the aspects that arise in the implementation of the Physical Twin, a generic dwelling abstraction. Second, the study focuses on the development of the Digital Twin, which extends beyond the generative model to include data collected in the real world and represented in the model. As a result, evaluating data collection in combination with the monitoring tools installed in the test room becomes a key element, and their analysis and management within the BIM environment is the final step of the experimental process.

This path is therefore proposed as a useful technique for validating simulation results and evaluating the model's reliability. It also establishes a cyclical framework of digital and interactive knowledge exchange to refine models and introduce new facility management logic.

\section{EXPERIMENTATION}

\subsection{Construction of the test room (Physical Twin)}

The test room is a 20-square-meter single-story temporary pavilion with a 25-centimeter thick base slab and a 2.4-meter average height. The test room has two fully opaque walls and two glass openings in the east and south directions to optimize the climatic impact. The north wall was built to be removable and replaceable so that various stratigraphies could be checked, as well as the type of structure (Fig. 3). Its specific conformation, in fact, allows it to be replaced with X-Lam panels instead of the prefabricated panels that constitute the Platform-Frame structure. In this first phase of the research, all four walls were built using Platform-Frame. Starting with the evolutionary algorithms' optimized solutions, a first wall was built in the test room, consisting of an $11 \mathrm{~cm}$ rockwool external insulation, $1.5 \mathrm{~cm}$ marine plywood, $12 \mathrm{~cm}$ glasswool between the structural elements and $5 \mathrm{~cm}$ glasswool behind the plasterboard. The algorithm calculated a transmittance of $0.131 \mathrm{~W} / \mathrm{sqmK}$ for this wall.

The single-pitch ventilated roof has an inclination of $10^{\circ}$ and it is made of glulam wood beams and $2.3 \mathrm{~cm}$ thick planking. Around 15 square meters of thin-film photovoltaic panels with storage batteries ensure the heat pump's function, which is needed for

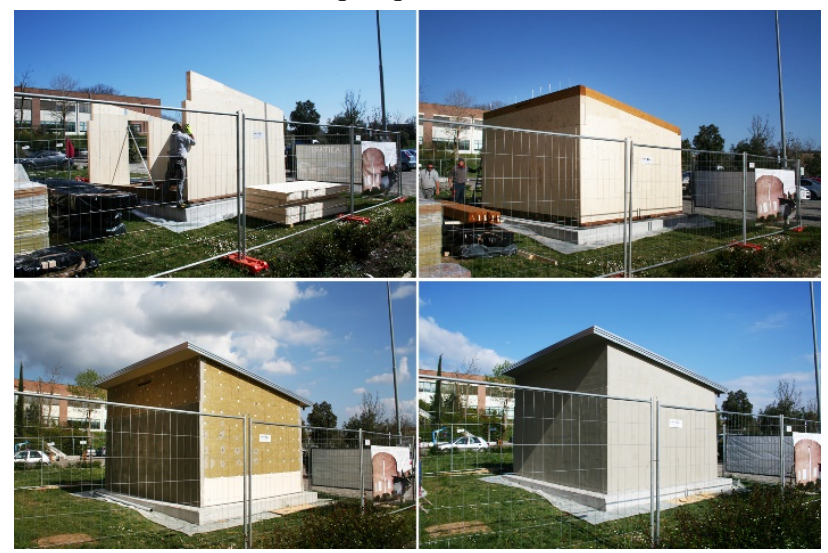

Figure 3. Different construction phases of the test room.

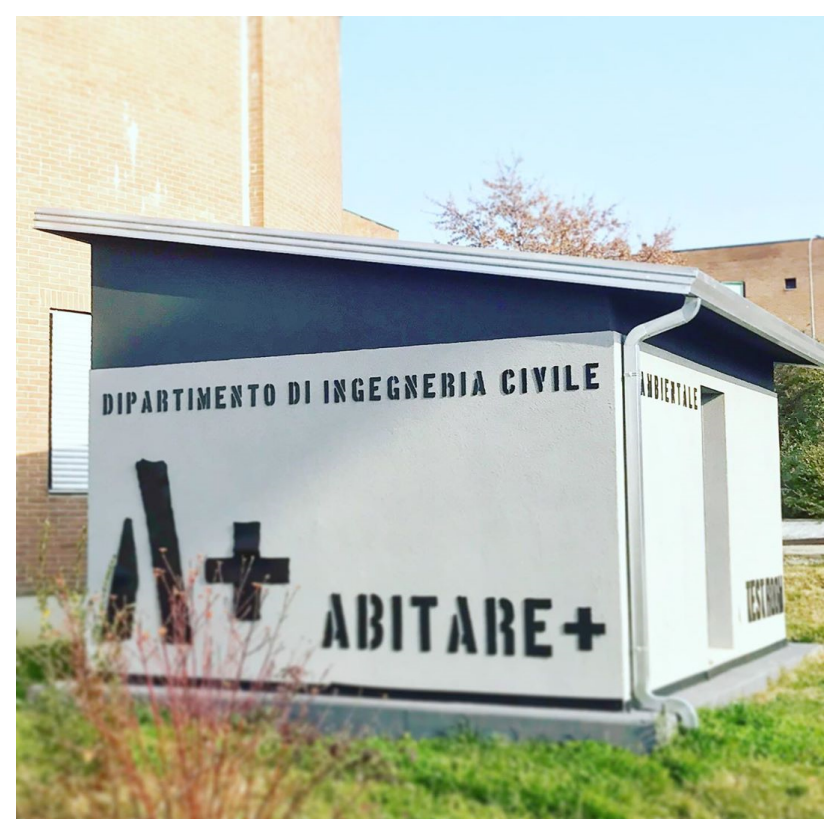

Figure 4. The completed test room.

cooling and heating in order to simulate typical indoor winter and summer thermo-hygrometric conditions (Fig. 4).

\subsection{Data collection}

Several sensors and instruments have been installed in the test room to monitor the parameters required to characterize the wall's efficiency. Both internally and externally, thermocouples are used to measure air and wall temperatures. The thermal transmittance $U$ of walls is measured using fluxmeters. Temperature and humidity probes test the indoor and outdoor air's temperature and relative humidity. The S.A.L.E. monitoring system allows for on-site monitoring of the wood's moisture content, identifying any irregularities that may lead to biodegradation. Wireless sensors and tools for collecting, storing, and managing alert messages are used in the monitoring. All sensors are visible and removable (Fig. 5).

The north-facing wall is tested because it is not directly exposed to solar radiation, which would influence the results, whereas the east-facing wall was also tracked as a reference. Monitoring was conducted through the previously described sensors during the summer period. The acquired data were used to determine the transmittance in situ, which was compared to the one simulated by the algorithm, according to UNI ISO 9869 ('ISO 9869-1:2014 Thermal insulation - Building elements - In-situ measurement of thermal resistance and thermal transmittance - Part 1: Heat flow meter method', 2014), which states that the thermal resistance can be calculated from the ratio between the summation of the surface temperature difference between outside and inside with the summation of the thermal fluxes (Eq. 1).

$$
R=\frac{\sum_{j=1}^{n}\left(T_{s i j}-T_{s e j}\right)}{\sum_{j=1}^{n} q_{j}}
$$

where $\quad T_{s i j}=$ internal surface temperature obtained from the $\mathrm{j}$ th measurement

$T_{s e j}=$ external surface temperature obtained from the $\mathbf{j}$ th measurement

$q=$ heat flux obtained from the $\mathrm{j}$-th measurement 


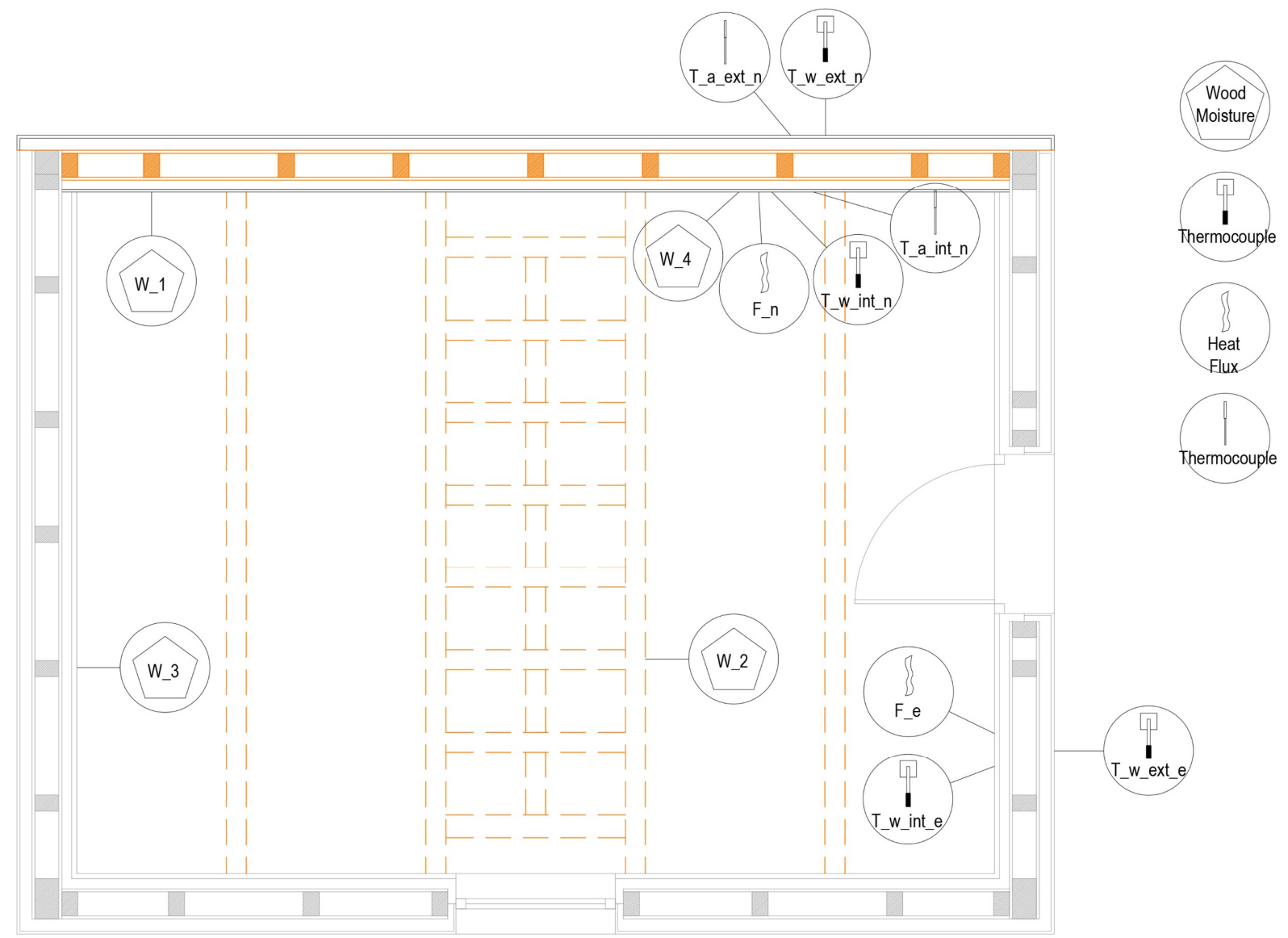

Figure 5. Plan view with the different sensors positioned in the test room.

$$
L=\frac{1}{R}
$$

Thermal transmittance is calculated by taking into account air temperatures as well as internal and external surface resistances (Eq. 3):

$$
U=\frac{\sum_{j=1}^{n} q_{j}}{\sum_{j=1}^{n}\left(T_{i j}-T_{e j}\right)}
$$

where $T_{i j}=$ internal temperature obtained from the $\mathrm{j}$-th measurement

$T_{e j}=$ external temperature obtained from the $\mathrm{j}$-th measurement

The measurements were taken over four days in July, with reasonably significant daily variations in the outdoor temperature (between 44 and $20^{\circ} \mathrm{C}$ ) and night time values never dropping below the indoor temperature (constant at $20^{\circ} \mathrm{C}$ ), resulting in a sufficiently high temperature gradient.

As a result of the acquisitions, the following parameters have been obtained:

Thermal resistance: $\mathrm{R}=5.233 \mathrm{mqK} / \mathrm{W}$

Conductance: $\mathrm{L}=0.191 \mathrm{~W} / \mathrm{mqK}$

Thermal transmittance: $\mathrm{U}=0.185 \mathrm{~W} / \mathrm{mqK}$
The transmittance measurement should be adjusted by a $10 \%$ percentage error due to direct measurement. Furthermore, the specified thermal conductivity values, which were used in the algorithm's calculation, are accurate for test conditions at $10{ }^{\circ} \mathrm{C}$. On the basis of these considerations and the required corrections, it can be assumed that real behaviour closely matches that obtained from the simulations.

\subsection{Realization of the Digital Twin}

The information is returned from the built to the digital in the final section of the study, in order to build a real-time monitoring system of what is happening within the test room and integrate that data into the model, creating a digital twin in the BIM environment. In fact, the test room has been remodelled in Revit As-Built, with symbolic elements placed to indicate the location of the specific sensors in the test room that perform realtime monitoring. Special families have been used for this purpose, through the "Generic Models" family, whose instances have been modelled by spheres. Different colored spheres are correlated with parameters and details that can be seen remotely in space in real time. Depending on the type of sensor, four different sphere types have been created: air temperature (blue spheres), wall temperature (red spheres), thermal flux (orange spheres), and wood moisture (brown spheres). After that, the different instances were connected to the .csv files that are continuously updated based on the measurement interval set (generally every 60 seconds). Each instance has been placed near the wall where the sensor it represents is actually located, and the 


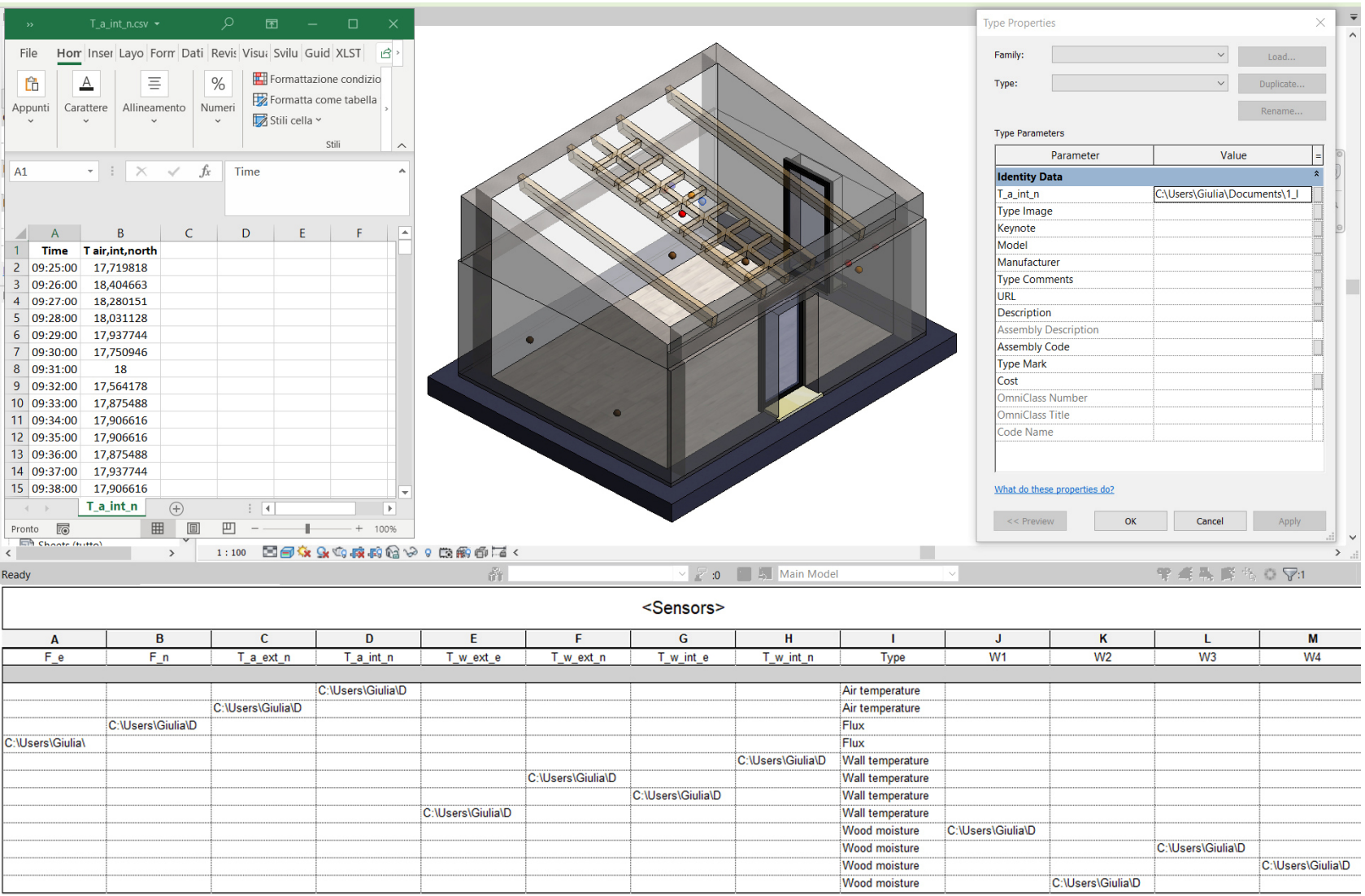

Figure 6. The different spheres have been positioned and colored according to the corresponding sensors in the test room.

relation between the different instances and the corresponding .csv files can be seen through the abacus of the sensors (Fig. 6). The benefit of automatically collecting the real data measured by the sensors is then combined with the ability to track temperatures, flows, and humidity values punctually in space and time through their real-time visualization, which can be accessed remotely. Another factor is the ability to send the data obtained in the Digital Twin back into the initial algorithm used to simulate the energy output of the various walls: this exchange is useful to refine the algorithm's measurement method in order to make the preliminary step simulation even more precise (Fig. 7).

\section{CONCLUSIONS}

The developed research emphasizes the importance of representation in digital modelling, with particular attention to the digitization process and the convergence of various aspects of the form into virtual computational tools. Models gather and analyze data and information through interconnected and interdisciplinary routes in order to transform it into knowledge. Because of its transdisciplinary nature, representation becomes the language of knowledge incorporation, introducing its own field of experimental and heuristic intervention, with paths that must be validated.

The relationships between virtual and physical space provide a complex view of procedures that become cyclical. In fact, the approach starts from the algorithms of parametric multioptimization of the walls to determine combinations of materials and thicknesses in relation to costs and performances. These simulated features must then be validated using sensors, whose data are sent back into the models to verify initial assumptions. This approach enhances the very role of the model in its relationship with information: data is managed and visualized,
DIGITAL SIMULATION

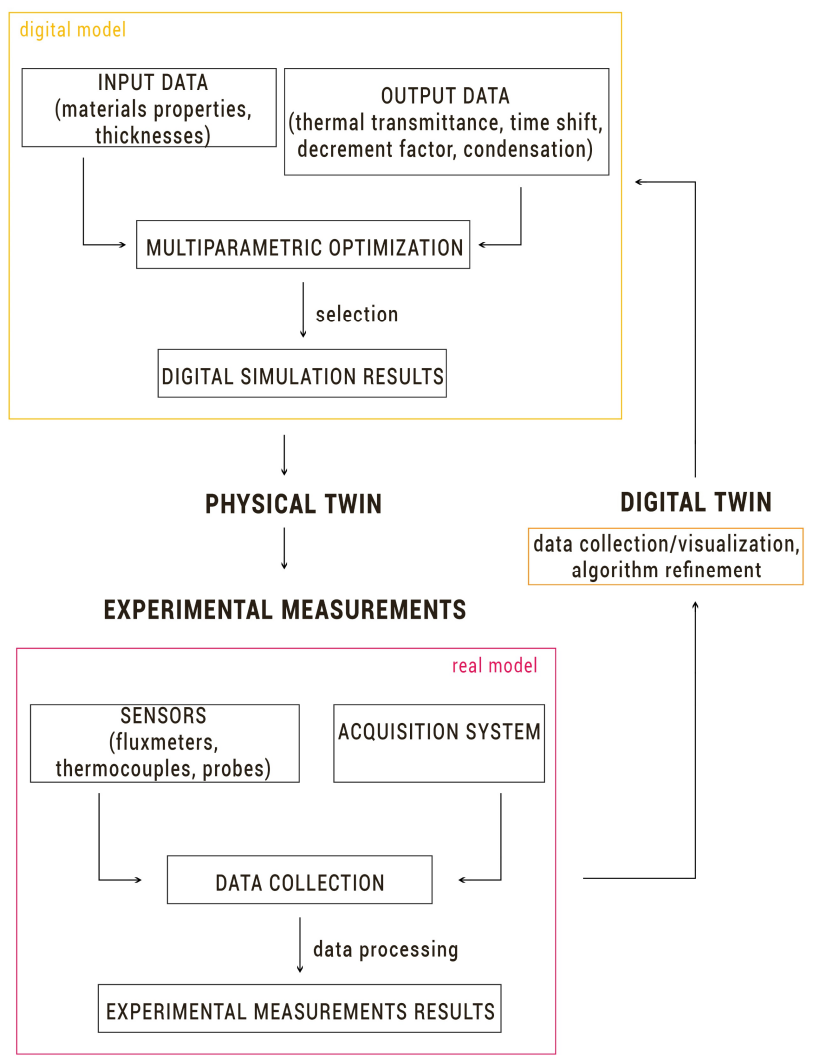

Figure 7. The process begins with a digital simulation that leads the development of the Physical Twin. The data obtained from the real model's sensors are sent to the Digital Twin, which allows the initial algorithm to be refined. 
but it can also be used to dynamically and accurately explain what is happening in reality. It is then simple to link the data to alarms and home automation systems, which can then be used to turn on/off cooling or heating, for example. Even at this early stage, the Digital Twin appears to be useful in simulating and predicting future behavior, optimizing resource and time usage, and generally improving management efficiency. In this way, an information ecosystem is generated, which creates knowledge and provides data for different purposes, depending on particular interests. The resulting process aids in the structure of resilient processes to anticipate, respond, and react to what, due to its complexity, can only be controlled by digital and understood by design.

\section{REFERENCES}

Anderson DM. 2002. Build-to-order and mass customization: the ultimate supply chain management and lean manufacturing strategy for low-cost on-demand production without forecasts or inventory. CIM Press: Cambria.

Aste N, Leonforte F, Manfren M, Mazzon M. 2015. Thermal inertia and energy efficiency - Parametric simulation assessment on a calibrated case study. Applied Energy 145: 111-123.

Barlish K, Sullivan K. 2012. How to measure the benefits of BIM - A case study approach. Automation in Construction 24: 149159.

Batty M. 2018. Digital twins. Environment and Planning B: Urban Analytics and City Science 45: 817-820.

Bergmann E, Hildebrand S. 2015. Form-finding, form-shaping, designing architecture. Mendrisio Academy Press: Mendrisio.

Bianconi F, Filippucci M. 2017. Generative Education: Thinking by Modeling/Modeling by thinking. In Architectural Draughtsmanship Springer: Cham; 1009-1020.

Bianconi F, Filippucci M. 2019a. Digita Wood Design Innovative Techniques of Representation in Architectural Design.

Bianconi F, Filippucci M. 2019b. WOOD, CAD AND AI: Digital modelling as place of convergence of natural and artificial intelligent to design timber architecture.

Bianconi F, Filippucci M, Buffi A. 2019. Automated design and modeling for mass-customized housing. A web-based design space catalog for timber structures. Automation in Construction 103.

Bryde D, Broquetas M, Volm JM. 2013. The project benefits of Building Information Modelling (BIM). International Journal of Project Management 31: 971-980.

Cabeza LF, Barreneche C, Miró L, Morera JM, Bartolí E, Inés Fernández A. 2013. Low carbon and low embodied energy materials in buildings: A review. Renewable and Sustainable Energy Reviews 23: 536-542.

Chen L, Sass L. 2017. Generative computer-aided design: multimodality large-scale direct physical production. Computer-Aided Design and Applications 14: 83-94.

Dainty A, Leiringer R, Fernie S, Harty C. 2015. Don't Believe the (BIM) Hype: The Unexpected Corollaries of the UK 'BIM
Revolution. In EPOC 2015 Conference Ubijournal: New Delhi;

Diakaki C, Grigoroudis E, Kolokotsa D. 2008. Towards a multiobjective optimization approach for improving energy efficiency in buildings. Energy and Buildings 40: 1747-1754.

Directive (EU) 2018/844 of the European Parliament and of the Council of 30 May 2018 amending Directive 2010/31/EU on the energy performance of buildings and Directive 2012/27/EU on energy efficiency. 2018.

Directive 2010/31/EU of the European Parliament and of the Council of 19 May 2010 on the energy performance of buildings. 2010. : 124-146.

Eastman CM. 2011. BIM handbook: a guide to building information modeling for owners, managers, designers, engineers and contractors. John Wiley \& Sons: Hoboken.

Falamarzi Z, Correa Zuluaga D. 2019. Robotic assembly of a structurally informed wall system using standard and nonstandard components. In Proceedings of International Conference on Emerging Technologies In Architectural Design (ICETAD2019) 239-248.

Glaessgen EH, Stargel DS. 2012. The digital twin paradigm for future NASA and U.S. Air force vehicles. In Collection of Technical Papers - AIAA/ASME/ASCE/AHS/ASC Structures, Structural Dynamics and Materials Conference.

Gramazio F, Kohler M, Langenberg S. 2014. FABRICATE: negotiating design \& making. UCL Press: Zürich.

Gubbi J, Buyya R, Marusic S, Palaniswami M. 2013. Internet of Things (IoT): A vision, architectural elements, and future directions. Future Generation Computer Systems 29: 1645-1660.

Hemmerling M, Cocchiarella L (Eds.). 2018. Informed architecture: computational strategies in architectural design. Springer: Cham.

Hoadley RB. 2000. Understanding Wood: A Craftsman's Guide to Wood Technology. Taunton Press.

Holstov A, Farmer G, Bridgens B. 2017. Sustainable Materialisation of Responsive Architecture. Sustainability 9: 435.

Iansiti M, Lakhani KL. 2015. Digital Ubiquity: How Connections, Sensors, and Data Are Revolutionizing Business. CFA Digest 45: dig.v45.n2.8.

ISO 9869-1:2014 Thermal insulation - Building elements - Insitu measurement of thermal resistance and thermal transmittance — Part 1: Heat flow meter method. 2014.

Kamarul Bahrin MA, Othman MF, Nor Azli NH, Talib MF. 2016. INDUSTRY 4.0: A REVIEW ON INDUSTRIAL AUTOMATION AND ROBOTIC. Jurnal Teknologi 78.

Khanzode A, Fischer M, Reed D. 2008. Benefits and lessons learned of implementing building virtual design and construction (VDC) technologies for coordination of mechanical, electrical, and plumbing (MEP) systems on a large healthcare project. ITcon 13: 324-342.

Kolarevic B. 2015. From Mass Customisation to Design 
'Democratisation"', Architectural Design 85: 48-53.

Lenka S, Parida V, Rönnberg Sjödin D, Wincent J. 2016. Digitalization and advanced service innovation: How digitalization capabilities enable companies to co-create value with customers. Management of Innovation and Technology: 35 .

Marszal AJ, Heiselberg P, Bourrelle JS, Musall E, Voss K, Sartori I, Napolitano A. 2011. Zero Energy Building - A review of definitions and calculation methodologies. Energy and Buildings 43: 971-979.

Menges A. 2009. Performative Wood: Integral Computational Design for Timber Constructions. In Building a Better Tomorrow - Proceedings of the 29th Annual Conference of the Association for Computer Aided Design in Architecture, d'Estrée. Sterk T, , Loveridge R, Pancoast D (eds). Association for ComputerAided Design in Architecture: Chicago; 66-74.

Menges A, Schwinn T, Krieg OD (Eds.). 2017. Advancing Wood Architecture. Routledge: London.

Mitchell WJ. 1995. City of bits : space, place, and the infobahn. MIT Press: Cambridge.

O'Connor J, Dangerfield J. 2004. The Environmental Benefits of Wood Construction. In Proceedings of the 8th World Conference on Timber Engineering, vol 1 171-177.

Oxman R, Oxman R. 2010. The new structuralism: design, engineering and architectural technologies. Wiley: New York.

Paoletti I. 2017. Mass customization in the era of industry 4.0: Towards immaterial building technology. In Informed Architecture: Computational Strategies in Architectural Design Springer International Publishing; 77-87.

Pine BJ, Slessor C. 1999. Mass customization: the new frontier in business competition. Harvard Business School: Boston.

Rodriguez-Ubinas E, Montero C, Porteros M, Vega S, Navarro I, Castillo-Cagigal M, Matallanas E, Gutiérrez A. 2014. Passive design strategies and performance of Net Energy Plus Houses. Energy and Buildings 83: 10-22.

Rossi M, Rocco VM. 2014. External walls design: The role of periodic thermal transmittance and internal areal heat capacity. Energy and Buildings 68: 732-740.

Schumacher P. 2011. The autopoiesis of architecture: a new framework for architecture. John Wiley \& Sons: West Sessex.

Schwab K. 2016. The fourth industrial revolution. World Economic Forum: Ginevra.

Seccaroni M, Pelliccia G. 2019. Customizable social wooden pavilions: A workflow for the energy, emergy and perception optimization in perugia's parks. In Digital Wood Design. Innovative Techniques of Representation in Architectural Design Springer; 1045-1062.

Shi X, Yang W. 2013. Performance-driven architectural design and optimization technique from a perspective of architects. Automation in Construction 32: 125-135.

Smith P. 2014. BIM Implementation - Global Strategies.
Procedia Engineering 85: 482-492.

Tian Z, Zhang X, Jin X, Zhou X, Si B, Shi X. 2018. Towards adoption of building energy simulation and optimization for passive building design: A survey and a review. Energy and Buildings 158: 1306-1316.

Ugolev BN. 2014. Wood as a natural smart material. Wood Science and Technology 48: 553-568.

Wang W, Zmeureanu R, Rivard H. 2005. Applying multiobjective genetic algorithms in green building design optimization. Building and Environment 40: 1512-1525.

Weinand Y. 2016. Advanced timber structures: architectural designs and digital dimensioning. Birkhäuser: Basel.

Willmann J, Gramazio F, Kohler M. 2017. New paradigms of the automatic: robotic timber construction in architecture,. In Advancing Wood Architecture. A Computational Approach, Menges A, , Schwinn T, , Krieg OD (eds). Routledge: London; $13-28$.

Wood DM, Correa D, Krieg OD, Menges A. 2016a. Material computation-4D timber construction: Towards building-scale hygroscopic actuated, self-constructing timber surfaces. International Journal of Architectural Computing 14: 49-62.

Wood DM, Correa D, Krieg OD, Menges A. 2016b. Material computation-4D timber construction: Towards building-scale hygroscopic actuated, self-constructing timber surfaces. International Journal of Architectural Computing 14: 49-62.

Wood handbook - Wood as an engineering material. 2010. Forest Products Laboratory Department of Agriculture, Forest Service: Madison, WI: U.S.

Wright JA, Loosemore HA, Farmani R. 2002. Optimization of building thermal design and control by multi-criterion genetic algorithm. Energy and Buildings 34: 959-972.

Xu L Da, He W, Li S. 2014. Internet of Things in Industries: A Survey. IEEE Transactions on Industrial Informatics 10: 22332243.

Zheng Y, Yang S, Cheng H. 2019. An application framework of digital twin and its case study. Journal of Ambient Intelligence and Humanized Computing 10: 1141-1153. 